\title{
Coronary computed tomography angiography: Star of the show or supporting act?
}

\author{
Vito D. Bruno, MD, PhD, and Mustafa Zakkar, MD, PhD, FRCS
}

\author{
From the Bristol Heart Institute, School of Clinical Sciences, University of Bristol, Bristol, United Kingdom. \\ Disclosures: Authors have nothing to disclose with regard to commercial support. \\ Received for publication Dec 4, 2017; accepted for publication Dec 18, 2017; available ahead of print Jan 31, \\ 2018. \\ Address for reprints: Vito D. Bruno, MD, PhD, Bristol Heart Institute, Faculty of Health Science, University of \\ Bristol, Marlborough St, Bristol BS2 8HW, United Kingdom (E-mail: Vito.D.Bruno@ bristol.ac.uk). \\ J Thorac Cardiovasc Surg 2018;155:1432-3 \\ $0022-5223 / \$ 36.00$ \\ Copyright (c) 2017 by The American Association for Thoracic Surgery \\ https://doi.org/10.1016/j.jtcvs.2017.12.077
}

Coronary angiography (CAG) is currently recommended as the gold standard for identifying coronary artery disease (CAD) in patients undergoing heart valves surgery. ${ }^{1,2}$ However, despite its wide use, it is not free of complications as the result of its invasive nature. ${ }^{3}$ Therefore, there remains a need for a valid alternative diagnostic tool. Over the last 10 years, several papers have been published that evaluate the reliability of coronary computed tomography angiography (CCTA) as a possible substitute. Moreover, a recently published meta-analysis ${ }^{4}$ demonstrated that CCTA can be very effective both in terms of sensitivity (93\%) and specificity $(89 \%)$. It is important to point that regardless of the value of the real impact of meta-analyses on clinical research, ${ }^{5}$ it has to be highlighted that this review involved only 1107 subjects and was affected by a certain degree of heterogeneity, especially in the presence of aortic valve stenosis.

Lee and colleagues ${ }^{6}$ in this issue of the Journal, in a nicely designed and well-conducted propensity score study to evaluate the clinical impact of CCTA in preoperative diagnosis of $\mathrm{CAD}$ in patients undergoing heart valve disease, found conflicting results. The authors have, in fact, showed a reduction in detection rates of CAD with CCTA. In the overall cohort, the authors saw a confirmation of CAD in $4.9 \%$ of the patients in the CCTA group compared with $9.7 \%$ in the CAG group $(P<.001)$, which was persistent after matching $(6.6 \%$ vs $11.2 \%$; $P=.007)$. Most importantly, there were 94 patients who underwent CAG although CCTA did not show a significant stenosis: in this subgroup, more than $10 \%$ of the patients were found to have significant stenosis at $\mathrm{CAG}$, demonstrating the reduced sensitivity of CCTA in detecting CAD. In contrast, in the group of patients with significant disease at CCTA, only 56\% were confirmed at CAG, thus showing also a small specificity of the CCTA. These differences were also reflected with the small number of coronary artery bypass grafts done in the CCTA group.

The study has also the benefit of evaluating clinical outcomes, demonstrating a significantly greater incidence of low cardiac output in the patients in the CCTA group

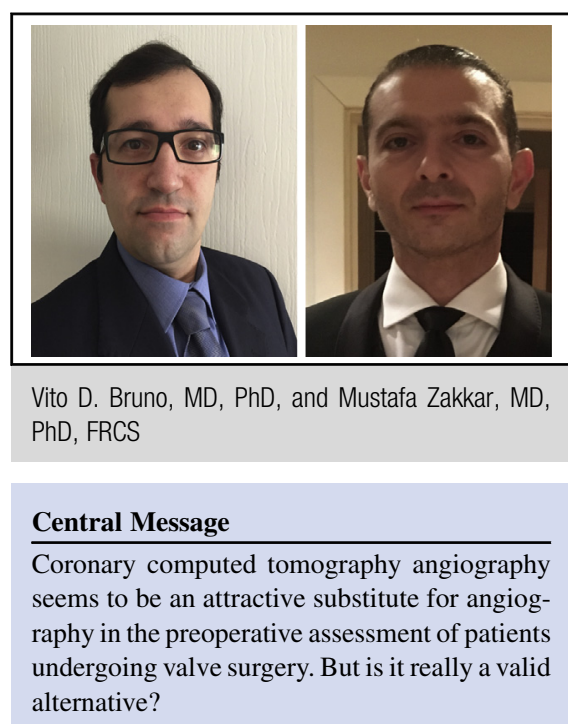

See Article page 1423.

but no differences in terms of 30-day mortality, postoperative stroke, and acute kidney injury rates. As shown in Table E3, most of the low cardiac output syndromes were related to perioperative myocardial infarction and, although it is not easy to discriminate the causative nature of these postoperative myocardial infarction, it can be speculated their possible relationship with undiagnosed coronary diseases. Furthermore, it is important to note the presence of a greater number of major adverse cardiac events in the CCTA group (although not statistically significant), which could be correlated with a reduced diagnosis of CAD.

Another important finding of this paper is the increased risk of developing acute kidney injury after surgery when CAG followed CCTA (which can be contrast related). In this sense, it would be better to consider CAG as the primary diagnostic tool, rather than delay the diagnosis and expose the patient to further risks. The study has some limitations, mainly related to its nonrandomized nature (partially addressed with the propensity score matching), but also to the lack of a systematic and predefined pathway of diagnostic assessment where some patients underwent both tests without clear definition of their disease. Despite these important limitations, it provides a good understanding of clinical impact of CCTA in a large cohort of patients and is probably the largest study of this type.

Overall, the real advantages of CCTA in identifying coronary disease are still to be demonstrated and until such time 
arrives, CAG remains the most reliable instrument to detect CAD before valve surgery. A prospective, randomized controlled trial would be the ideal way to address this topic. The technological improvements in the last few years have for sure increased the possible future role for CCTA to define CAD in such cohort of patients, but in our opinion, its largescale use in this setting appears to be less efficient and still far from being a mainstream practice.

\section{References}

1. Baumgartner H, Falk V, Bax JJ, De Bonis M, Hamm C, Holm PJ, et al. 2017 ESC/ EACTS Guidelines for the management of valvular heart disease. Eur Heart J. 2017;38:2739-86.
2. Nishimura RA, Otto CM, Bonow RO, Mack MJ, Carabello BA, McLeod CJ, et al 2017 AHA/ACC Focused Update of the 2014 AHA/ACC guideline for the management of patients with valvular heart disease. Circulation. 2017;135:e1159-95.

3. Tavakol M, Ashraf S, Brener S. Risk and complications of coronary angiography: a comprehensive review. Global J Health Sci. 2012;4:65-93.

4. Opolski MP, Staruch AD, Jakubczyk M, Min JK, Gransar H, Staruch M, et al. CT angiography for the detection of coronary artery stenoses in patients referred for cardiac valve surgery. Systematic review and meta-analysis. JACC Cardiovasc Imaging. 2016;9:1060-70

5. Packer M. Are meta-analyses a form of medical fake news? Thoughts about how they should contribute to medical science and practice. Circulation. 2017; 136: 2097-9.

6. Lee W, Kim JB, Yang DH, Kim C, Kim J, Ju MH, et al. Comparative effectiveness of coronary screening in heart valve surgery: computed tomography versus conventional coronary angiography. J Thorac Cardiovasc Surg. 2018;155: 1423-31.e3. 